\title{
Foreigner talk through word reduction in native/non-native spoken interactions*
}

\author{
SARA RODRIGUEZ-CUADRADO \\ Department of Psychology, Edge Hill University, Ormskirk, \\ United Kingdom \\ CRISTINA BAUS \\ Departament de Tecnologies de la Informació i les \\ Comunicacions Universitat Pompeu Fabra, Barcelona, Spain \\ ALBERT COSTA \\ Departament de Tecnologies de la Informació i les \\ Comunicacions Universitat Pompeu Fabra, Barcelona, Spain; \\ Institució Catalana de Recerca i Estudis Avançats
}

(Received: March 20, 2017; final revision received: June 16, 2017; accepted: July 07, 2017)

\begin{abstract}
We explore the properties of foreigner talk through word reduction. Word reduction signals that the speaker is referring to the same entity as previously and should be preserved for foreigner talk. However, it leads to intelligibility loss, which works against foreigner talk. Pairs of speakers engaged in a task where native speakers talked either to a native or non-native listener. Natives talking to non-natives performed foreigner talk for duration and intensity. Duration and intensity were reduced for native and non-native listeners equally. These results suggest that word reduction is insensitive to communicative adjustments in the context of foreign talk.
\end{abstract}

Keywords: word reduction, foreigner talk, non-native speakers, word duration, word intensity

\section{Introduction}

As native speakers, we make considerable efforts to accommodate our speech to the needs of non-native listeners, a phenomenon known as foreigner talk. Native speakers talking to non-native listeners tend to speak slower and louder than when speaking to native listeners. Also, they show less vowel reduction, avoid idiomatic expressions, or use high frequency words and simple syntactic constructions. Natives talking to non-natives also include more repetitions and clarifications (for a review see Wooldridge, 2001; see also Arthur, Weiner, Culver, Lee \& Thomas, 1980; Ferguson, 1971; Henzl, 1979; Long, 1983; Nelson, 1992; Ramamurti, 1980; Scarborough, Dmitrieva, Hall-Lew, Zhao \& Brenier, 2007; Tarone, 1980). Here we focus on the acoustic adjustments that characterize foreign talk to investigate its impact on one pervasive phenomenon in dialogue, namely word reduction (see Aylett \& Turk, 2004; Baker \& Bradlow, 2009; Bell, Gregory, Brenier, Jurafsky, Ikeno \&

\footnotetext{
* This work was supported by grants from the Spanish Government (PSI2011-23033, Consolider Ingenio 2010 CSD2007-00012) and the Catalan government (Consolidat SGR 2009-1521). Sara RodríguezCuadrado was supported by a predoctoral fellowship from the Spanish Government (FPU 2008-2012). Cristina Baus was supported by the People Program (Marie Curie Actions, FP7- PEOPLE 2014-2016) under REA agreement $n^{\circ} 623845$. We would like to thank Sumeer Chadha, Joanna Corey and Carlos Romero-Rivas for their assistance during data recruitment and manuscript elaboration.
}

Girand, 2002; Jurafsky, Bell, Gregory \& Raymond, 2001). In particular, we assess whether word reduction is affected by the acoustic adjustments of foreigner talk.

One way to explore word reduction is repetition in a given communicative interaction. Repeated words are characterized by having shorter durations, reduced intensities and narrower pitch as compared to when words are introduced for the first time in the discourse (see Baker \& Bradlow, 2009; Bell et al., 2002; Bell, Jurafsky, Fosler-Lussier, Girand, Gregory \& Gildea, 2003; Clark \& Haviland, 1977; Fowler \& Housum, 1987; Gregory, Raymond, Bell, Fosler-Lussier \& Jurafsky, 1999; Lieberman, 1963; Samuel \& Troicki, 1998; Watson, Arnold \& Tanenhaus, 2008). Beyond single words, repetition also leads to the shortening of referential expressions, meaning that the first time that a referent is introduced in the discourse, it tends to be longer and more explicit than its subsequent times (Ariel, 1990; Chafe, 1994; Galati \& Brennan, 2010; Grosz, Joshi \& Weinstein, 1995; Gundel, Hedberg \& Zacharski, 1993).

Crucially, word reduction has two particular features that deserve attention to deepen our understanding of foreigner talk. First, reduced words are identified as referring to a previously mentioned entity, and this has a positive effect in the listener's comprehension as it signals that the focus is on the same referent than before and no new information is introduced (see Birch \& Clifton, 1995; Terken \& Noteboom, 1987). In the context of foreigner talk, it might seem obvious that speakers would 
reduce words and keep the listener on track. However, reducing words implies reduced articulation in speech, which may lead also to a loss of intelligibility (Bard \& Aylett, 1999; Fowler \& Housum, 1987; Lieberman, 1963), which could have harmful effects on non-natives' language comprehension.

The only evidence of the production of word reduction in the context of communicative difficulties comes from clear speech. Clear speech is used, for example, when speakers talk to listeners having a perceptual difficulty (e.g., hearing problems). Baker and Bradlow (2009) asked participants to read paragraphs containing repeated words in two registers: plain and clear speech. The results showed that clear speech led to longer overall durations than plain speech. Importantly, repeated words were shortened in both plain and clear speech, which signals the existence of word reduction regardless of the linguistic difficulties of the interlocutor. The results of Baker and Bradlow (2009) suggest that word reduction might also be present in foreigner talk. However, their study involved single participants reading out loud as if they were talking to someone; therefore it is important to test whether the same occurs in the communicative context in which the speaker is more likely to take into consideration the limitations of his/her interlocutor.

Additionally, the work of Bradlow and Alexander (2007) can support the possibility that non-native speakers benefit from word reduction. Native and non-native listeners performed a sentence-in-noise recognition task, and non-natives were as able as natives to benefit from contextual information when provided with a clear signal. However, it is still possible that non-natives have trouble decoding an attenuated acoustic signal due to potential difficulties in their second language. That is, non-native speakers have performed worse than native speakers in speech recognition studies that provided with background noise or reverberation in comparison to more favorable listening conditions (see Nábelek \& Donahue, 1984; Takata \& Nábelek, 1990; Mayo, Florentine \& Buus, 1997; Meador, Flege \& MacKay, 2000; Rogers, Lister, Febo, Besing \& Abrams, 2006). This poorer performance could be explained by the lower experience of the non-native at any level of language (Bradlow \& Alexander, 2007). If the lower experience of non-natives jeopardized their speech comprehension, the pragmatic contribution of reduction might be irrelevant as long as the listener is not able to decode the words.

Here we expand the studies of Baker and Bradlow (2009) and Bradlow and Alexander (2007) by exploring how word reduction is affected in the context of foreign talk and in a communicative setting.

Our study involved two speakers engaged in a collaborative "map" task (we use this terminology for the sake of simplicity; see "Procedure" for more details). There were two groups. One of the speakers was always a
Spanish native speaker. However, the difference between groups is that the other participant (a confederate) was either a Spanish native speaker or an English native speaker interacting in his second language, Spanish. Therefore, we explored how word reduction behaves in "native" conversational settings (between two native speakers) and, crucially, in the context of foreigner talk (between a native and a non-native speaker). We contemplate two possibilities. First, that native speakers would not reduce words when talking to non-natives in order to keep speech more intelligible. Second, that natives could both reduce words and enhance speech through foreigner talk. We subscribe to the second possibility due to the previous evidence supporting foreigner talk (Campbell, Gaskill \& Vander Brook, 1977; Ferguson, 1971; James, 1986; Lattey, 1981) and the interaction between word reduction and clear speech in word duration (as in Baker \& Bradlow, 2009).

\section{Method}

\section{Participants}

28 Spanish native speakers, students at the Universitat Pompeu Fabra in Barcelona (mean age: 28.3 years, sd: $5.81 ; 17$ female) took part in the experiment (15 participants were assigned to interact with a native speaker and 13 with a foreign speaker). They received 7 euro for their participation. All participants had normal or corrected-to-normal vision and none of the participants reported having any speech or hearing impairments.

Two confederates aided in the study. The Spanish native confederate was a monolingual young female. The foreign speaker was a young American male, non-native speaker of Spanish.

\section{Procedure}

We adapted Fraundorf, Watson and Benjamin's (2015) collaborative map task. The speaker was presented with a sequence of 6 "maps" (see Figure 1), plus a practice map, showed on a computer screen using DMDX (Forster \& Forster, 2003). In each map, there were two arrays of four objects, four were displayed in a string in the upper part of the map and four in the lower part, where two objects were linked in eight consecutive steps per map. Each object was involved in two different links, whose direction could be horizontal (two objects in the same string in the upper or lower part of the screen), vertical (two objects in the same axis in different strings from the upper to the lower or from the lower to the upper part of the screen) or diagonal (two objects in different axis in different strings from the upper to the lower or from the lower to the upper part of the screen). 
1
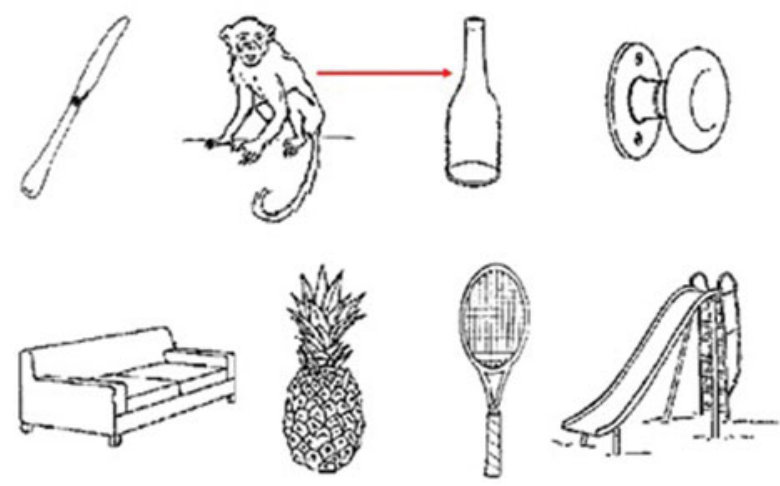

Figure 1. (Colour online) depicts an example of a map used by native/native pairs and native/non-native pairs.

Concretely, the figure shows the map seen by the speaker in a computer screen. Listeners had the same maps in paper with no links (in this case, an arrow from the monkey to the bottle).

The confederate (listener) had exactly the same 6 maps (plus the practice map) that the speaker had, but printed on paper and with no links between the objects. The task of the speaker was to tell the listener which were the two linked objects and in which direction, by giving instructions aloud of the type "go from the monkey (object 1) to the bottle (object 2)". Then the task of the listener was to draw an arrow linking the two mentioned objects. For the "native/native" interaction, the listener was always the same female Spanish confederate. For the "native/non-native" interaction, the confederate was always the same American native male speaker, nonnative speaker of Spanish. Two actions were taken in order to offer cues about the proficiency of the listener. First, as the dyad was introduced, the experimenter asked the confederate for how long he had lived in Spain. The confederate always answered "for about a year" (in Spanish). Secondly, there were several moments (marked in the map, and randomized across subjects) during the task where the confederate showed confusion through questions like "from where did you say? /to where did you say?". Each instruction remained on the screen until the speaker pressed the spacebar, once the instruction was uttered. Participants were seated face to face in a soundproof booth and they could not see each other's map. Analyses of utterances were blind to the experimenter. There were a total of 96 utterances per participant (6 maps x 8 objects per map x 2 mentions per object). The task lasted approximately 20 minutes.

\section{Stimuli}

Items consisted of 48 Spanish words, which were mentioned twice (see Appendix 1). They were randomly distributed regarding 1) the map to which a particular item belonged to (6 options); 2 ) the order in which the items were displayed in the map's arrays ( 8 options); $3)$ the order in which the items were mentioned (2 options) and 4) the other item with which they were paired (7 options). Half of the items were mentioned in first place within the sentence of instruction and half of the items were mentioned in second place (that is, in half of the occasions the instruction would be "go from the monkey to the bottle", whereas on the other half "go from the bottle to the monkey"). This feature was randomized between participants. Repetitions were not immediate through maps but there were between 1 and 13 intermediate words between mentions (depending on the randomization in the mention order). Drawings were selected from several sources (including the Snodgrass database (Snodgrass \& Vanderwart, 1980) and the International Picture Naming Project (Szekely, Jacobsen, D'Amico, Devescovi, Andonova, Herron, Lu, Pechmann, Pleh, Wicha, Federmeier, Gerdjikova, Gutierrez, Hung, Hsu, Iyer, Kohnert, Mehotcheva, Orozco-Figueroa, Tzeng, Tzeng, Arevalo, Vargha, Butler, Buffington \& Bates, 2004).

\section{Measures indexing word reduction}

We used word duration and intensity as proxies for word reduction. Values were extracted using Praat version 5.3.15 (Boersma \& Weenink, 2008). Word duration is reported in milliseconds (ms) reflecting the mean in duration for the whole word. Word intensity is reported in decibels $(\mathrm{dB})$ reflecting the mean in intensity for the whole word. Word duration was extracted manually focusing on the beginning and end of the word and by listening carefully to each word and examining the visual waveform. Once duration is selected, intensity can be obtained automatically in Praat (Boersma \& Weenink, 2008). Duration and intensity were extracted in a blind way so it was not possible to know whether the word referred to a first or to a second mention.

\section{Data analysis}

Data obtained regarding the measures of duration and intensity were analyzed by fitting independent Generalized Linear Mixed Effects models with the lme4 library in R (Bates, Maechler \& Dai, 2008; see also Baayen, Davidson \& Bates, 2008; R Development Core Team, 2010). First, for each of these measures, datapoints 2.5 standard deviations above or below participants' mean were identified as outliers and discarded from the analysis. The two factors of interest, Mention and Group, were contrast-coded and centered. 
Table 1. First mentions'values, second mentions' values and foreigner talk effect for Duration.

\begin{tabular}{llll}
\hline \hline Duration & First mention & Second mention & Word reduction effect \\
\hline Native listener & $409,9 \mathrm{~ms}$ & $384,9 \mathrm{~ms}$ & $25 \mathrm{~ms}$ \\
Non-native listener & $530 \mathrm{~ms}$ & $501,9 \mathrm{~ms}$ & $28,1 \mathrm{~ms}$ \\
Foreign talk effect & $120,1 \mathrm{~ms}$ & $117 \mathrm{~ms}$ & \\
\hline \hline
\end{tabular}

Table 2. First mentions' values, second mentions' values and foreigner talk effect for Intensity.

\begin{tabular}{llll}
\hline \hline Intensity & First mention & Second mention & Word reduction effect \\
\hline Native listener & $48,7 \mathrm{~dB}$ & $47,6 \mathrm{~dB}$ & $1,1 \mathrm{~dB}$ \\
Non-native listener & $58,2 \mathrm{~dB}$ & $57,4 \mathrm{~dB}$ & $0,8 \mathrm{~dB}$ \\
Foreign talk effect & $9,5 \mathrm{~dB}$ & $9,8 \mathrm{~dB}$ & \\
\hline \hline
\end{tabular}

Duration and intensity were analyzed separately. Different models (maximum likelihood fit) were compared step-wise by means of log likelihood tests to identify the optimal linear mixed-effects model (Barr, Levy, Scheepers \& Tily, 2013). In particular, we applied a forward model comparison, from the simplest model including one fixed factor (Mention/Group) and random intercepts (Subjects/Items) to a more complex model including fixed factors, random intercepts and random slopes. In addition to our variables of interest, Mention and Group, models included other variables such as the Cognate Status of the words, the Distance between words (from 1 to 13) and Lexical Frequency, which might have an impact on word reduction (see, for instance, Gregory et al., 1999; Jurafsky et al., 2001). Model comparison was done in two steps. First, we selected the optimal linear mixed model including fixed factors and random intercepts. Second, the obtained model was compared with models including random slopes for subjects and items. For both measures, a model including Mention and Group and the interaction between Mention and Distance between mentions as fixed factors, Subjects and Items as random intercepts and random slopes (Mention for subjects and Distance between mentions for items) turned out to be a more optimal model (Duration: $\mathrm{AIC}=22258 ; \chi^{2}=6.5$, $\mathrm{p}=.03$; Intensity: AIC $=9517 ; \chi^{2}=403, p=.03$ ). Note that the model did not include the interaction between our factors of interest, Mention and Group, suggesting that these two factors were not significantly inter-dependent (therefore no significant interaction between them is expected). Thus, the results report the main effects of Mention, Group and Distance between mentions and the interaction between Mention and Distance.

\section{Results}

The results for duration and intensity for the two experimental groups and the corresponding mixed models analyses are reported in Tables 1 and 2 respectively. Data from natives speaking to natives in the first mention were considered as the intercept (baseline condition) against which the other levels were compared. Coefficient estimates and t-values (lmer.test package in R) are reported in the results section. The model included observations from 48 items and 28 participants. Note that positive coefficient and t-values indicate an increase for a given measure while negative indicates a decrease.

\section{Duration (measured in ms)}

As indicated in Table 1, the duration of the words was reduced significantly from the first to the second mention $(\beta=-28.2, \mathrm{SE}=6.8, t$-value $=-4.1, p<.001)$. Moreover, as indicated by the effect of Group $(\beta=58$, $\mathrm{SE}=13.2, t$-value $=4.3, p<.001)$, the duration of the words was longer in those interactions involving nonnative listeners. This result can be taken as an indication of foreign talk. The interaction between Mention and Distance between mentions was significant $(\beta=-2.3$, $\mathrm{SE}=0.9, t$-value $=-2.5, p<.001)$ suggesting that word reduction was greater for those words with a short lag between mentions.

\section{Intensity (measured in dB)}

As indicated in Table 2, word intensity was higher in the first than in the second mention $(\beta=-1.3, \mathrm{SE}=0.2$, 
Table 3. Coefficient and significant t-values

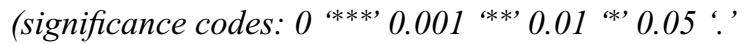
0.1 ' ' 1) for the predictors Duration and Intensity.

\begin{tabular}{|c|c|c|c|}
\hline Predictor: DURATION & Coefficient & SE & t-value \\
\hline \multicolumn{4}{|l|}{ Fixed effects } \\
\hline Intercept & 365 & 30.7 & $11.8^{* * *}$ \\
\hline Mention & -14 & 6.5 & $-2.1^{*}$ \\
\hline Group & 58 & 12.1 & $4.7^{* * *}$ \\
\hline Distance & 3.2 & 2.3 & 1.4 \\
\hline Mention: Distance & -2.3 & 0.9 & $-2.5^{*}$ \\
\hline \multicolumn{4}{|l|}{ Random effects } \\
\hline Participants & 3800 & & \\
\hline Items & 4444 & & \\
\hline Residual & 4966 & & \\
\hline Predictor: INTENSITY & Coefficient & SE & t-value \\
\hline \multicolumn{4}{|l|}{ Fixed effects } \\
\hline Intercept & 49.7 & 2.2 & $21.9^{* * *}$ \\
\hline Mention & -0.7 & 0.2 & $-3.4^{* * *}$ \\
\hline Group & 8.8 & 2.8 & $3^{* *}$ \\
\hline Distance & -.11 & 0.19 & -0.5 \\
\hline Mention: Distance & -0.03 & 0.03 & -1.1 \\
\hline \multicolumn{4}{|l|}{ Random effects } \\
\hline Participants & 58.4 & & \\
\hline Items & 39.1 & & \\
\hline Residual & 6 & & \\
\hline
\end{tabular}

$t$-value $=-4.7, p<.001)$, and it was also higher in the non-native group $(\beta=4.4, \mathrm{SE}=1.4, t$-value $=3.04, p<$ $.001)$, indicating the presence of foreigner talk. No other effect or interaction resulted significant (see Table 3 for more details on Duration and Intensity).

\section{Discussion}

We explored whether foreigner talk affects the magnitude of the word reduction phenomenon in an interactive setting. We asked participants to perform a map task, in which a native speaker gave directions aloud to a native or to a non-native confederate listener. Three main observations were made. First, native speakers performed foreigner talk when speaking to non-native listeners for both duration and intensity: in other words, they spoke more slowly and loudly to non-natives. Second, native speakers reduced words when such words have been already introduced in the conversation: that is, second mentions have a shorter duration and higher intensity. Third, the magnitude of the word reduction effect was similar in the two types of interactions. We also observed that word reduction for duration was stronger when there was a short lag between mentions. This particular aspect would be congruent with accounts such as the dual process model (Brown \& Dell, 1987; Bard, Anderson, Sotillo, Aylett, DohertySneddon \& Newlands, 2000), where reduction is driven by automatic processes as priming. Hence, priming effects would be stronger if the distance between mentions is short.

The presence of foreigner talk shows that native speakers take the characteristics (and maybe, the needs) of listeners into consideration. This evidence is congruent with previous findings on foreigner talk for duration and intensity (Chaudron, 1979; Henzl, 1979; Nelson, 1992; Ramamurti, 1980, Scarborough et al., 2007). Very relevantly, the current results show the word reduction phenomenon in a communicative scenario for duration and intensity in both native/native and in native/non-native interactions. Our results also extend previous findings as those by Baker and Bradlow (2009) and Bradlow and Alexander (2007) and challenge previous literature that has considered duration as the main and most reliable indicator to address word reduction - in comparison to intensity (Fowler \& Housum, 1987; Isaacs \& Watson, 2010; Lam \& Watson, 2010).

With respect to word reduction as a feature of foreigner talk (or the interaction between foreigner talk and word reduction), word duration and word intensity were reduced in a comparable way for native and non-native listeners. Therefore, foreigner talk and word reduction did not interact. As we already mentioned, reducing second mentioned words when talking to a non-native could be a double-edged sword. It can benefit the listener as it signals the informational status of words (as in "this word is new" or "this has already been presented"; Birch \& Clifton, 1995; Dahan, Tanenhaus \& Chambers, 2002; Fowler \& Housum, 1987; Terken \& Noteboom, 1987). However, as reduction involves hypo-articulation, it can challenge intelligibility (Bard \& Aylett, 1999; Fowler \& Housum, 1987; Lieberman, 1963) and lead to miscommunication as non-native speakers have lower experience than natives at any level of language (Bradlow \& Alexander, 2007). Our study suggests that although word reduction is performed, native speakers aid non-natives through foreigner talk. This is in line with previous evidence supporting foreigner talk (Campbell et al., 1977; Ferguson, 1971; James, 1986; Lattey, 1981) and also fits with related literature showing the interaction between word reduction and clear speech in word duration (Baker \& Bradlow, 2009).

To conclude, with a novel approach, our study replicates previous findings on foreigner talk and word reduction and shows that these effects coexist in native/non-native interactions. This result posits some limits to the foreign talk phenomenon by showing that word reduction is insensitive to the communicative adjustments that speakers make in the context of foreigner talk. 


\section{Supplementary Material}

For supplementary material accompanying this paper, visit https://doi.org/10.1017/S1366728917000402

\section{Appendix}

List of words employed in the study and their properties.

\begin{tabular}{|c|c|c|c|}
\hline Word (Spanish) & Word (English) & \#Letters & \#Syllables \\
\hline balanza & scale & 7 & 3 \\
\hline bandera & flag & 7 & 3 \\
\hline bate & bat & 4 & 2 \\
\hline bigote & moustache & 6 & 3 \\
\hline bolsa & bag & 5 & 2 \\
\hline botella & bottle & 7 & 3 \\
\hline botón & button & 5 & 2 \\
\hline brújula & compass & 7 & 3 \\
\hline cactus & cactus & 6 & 2 \\
\hline cámara & camera & 6 & 3 \\
\hline candado & lock & 7 & 3 \\
\hline cañón & cannon & 6 & 2 \\
\hline casco & helmet & 5 & 2 \\
\hline castillo & castle & 8 & 3 \\
\hline corona & crown & 6 & 3 \\
\hline corsé & corset & 5 & 2 \\
\hline cuchillo & knife & 8 & 3 \\
\hline dentista & dentist & 8 & 3 \\
\hline fresa & strawberry & 5 & 2 \\
\hline gamba & shrimp & 5 & 2 \\
\hline gato & cat & 4 & 2 \\
\hline gota & drop & 4 & 2 \\
\hline guitarra & guitar & 8 & 3 \\
\hline jirafa & giraffe & 6 & 3 \\
\hline maleta & suitcase & 6 & 3 \\
\hline melón & watermelon & 5 & 2 \\
\hline mono & monkey & 4 & 2 \\
\hline palmera & palm tree & 7 & 3 \\
\hline pañal & diaper & 5 & 2 \\
\hline patín & roller skate & 5 & 2 \\
\hline pecera & fish bowl & 6 & 3 \\
\hline peonza & spinning top & 6 & 3 \\
\hline piano & piano & 5 & 3 \\
\hline pingüino & penguin & 8 & 3 \\
\hline piña & pineapple & 4 & 2 \\
\hline pizza & pizza & 5 & 2 \\
\hline plato & plate & 5 & 2 \\
\hline pomo & knob & 4 & 2 \\
\hline pulpo & octopus & 5 & 2 \\
\hline raqueta & racket & 7 & 3 \\
\hline
\end{tabular}

Appendix. Continued.

\begin{tabular}{llll}
\hline \hline Word (Spanish) & Word (English) & \#Letters & \#Syllables \\
\hline rueda & wheel & 5 & 2 \\
silbato & whistle & 7 & 3 \\
sofá & sofa & 4 & 2 \\
tobogán & slide & 7 & 3 \\
trompeta & trumpet & 7 & 3 \\
túnel & tunnel & 5 & 2 \\
vaso & glass & 4 & 2 \\
vestido & dress & 7 & 3 \\
\hline \hline
\end{tabular}

\section{References}

Ariel, M. (1990). Accessing noun-phrase antecedents. London: Routledge.

Arthur, B., Weiner, R., Culver, M., Lee, Y. J., \& Thomas, D. (1980). The register of impersonal discourse to foreigners: Verbal adjustments to foreign accent. Discourse analysis in second language research, 111-124.

Aylett, M., \& Turk, A. (2004). The smooth signal redundancy hypothesis: A functional explanation for relationships between redundancy, prosodic prominence, and duration in spontaneous speech. Language and Speech, 47, 31-56.

Baayen, R. H., Davidson, D. J., \& Bates, D. M. (2008). Mixedeffects modeling with crossed random effects for subjects and items. Journal of Memory and Language, 59, 390-412.

Baker, R.E., \& Bradlow, A.R. (2009). Variability in word duration as a function of probability, speech style, and prosody. Language and Speech, 52, 391-413.

Bard, E. G., Anderson, A., Sotillo, C., Aylett, M. DohertySneddon, G., \& Newlands, A. (2000). Controlling the intelligibility of referring expressions in dialogue. Journal of Memory and Language, 42, 1-22.

Bard, E. G., \& Aylett, M. P. (1999). The disassociation of deaccenting, givenness, and syntactic role in spontaneous speech. In Proceedings of the 1999 international conference on spoken language processing (pp. 17531756).

Barr, D. J., Levy, R., Scheepers, C., \& Tily, H. J. (2013). Random effects structure for confirmatory hypothesis testing: Keep it maximal. Journal of Memory and Language, 68, 255278.

Bates, D., Maechler, M., \& Dai, B. (2008). lme4: Linear MixedEffects Models Using S4 Classes, Version 0.999375-28. R package.

Bell, A., Gregory, M. L., Brenier, J. M., Jurafsky, D., Ikeno, A., \& Girand, C. (2002). Which predictability measures affect content word durations? In ISCA Tutorial and Research Workshop (ITRW) on Pronunciation Modeling and Lexicon Adaptation for Spoken Language Technology.

Bell, A., Jurafsky, D., Fosler-Lussier, E., Girand, C., Gregory, M., \& Gildea, D. (2003). Effects of disfluencies, predictability, and utterance position on word form variation in English conversation. The Journal of the Acoustical Society of America, 113, 1001. 
Birch, S., \& Clifton, C. (1995). Focus, accent, and argument structure: Effects on language comprehension. Language and speech, 38, 365-391.

Boersma, P., \& Weenink, D. (2008). Praat: doing phonetics by computer,.Computer program available at $<$ http://www.praat.org.

Bradlow, A. R., \& Alexander, J. A. (2007). Semantic and phonetic enhancements for speech-in-noise recognition by native and nonnative listeners. The Journal of the Acoustical Society of America, 121, 2339.

Brown, P. M., \& Dell, G. S. (1987). Adapting production to comprehension: The explicit mention of instruments. Cognitive Psychology, 19(4), 441472

Campbell, C., Gaskill, W., \& Vander Brook, S. (1977). Some aspects of Foreigner Talk. In C.A. Henning (Ed.), Proceedings of the Los Angeles Second Language Forum (pp. 94-106). Los Angeles: University of California, Los Angeles.

Chaudron, C. (1979, February). Complexity of teacher speech and vocabulary explanation/elaboration. In 13th Annual TESOL Convention, Boston, Massachusetts.

Clark, H. H., \& Haviland, S. E. (1977). Comprehension and the given-new contract. In R. O. Freedle (Ed.), Discourse production and comprehension. Discourse Processes: Advances in Research and Theory, 1, (pp. 1-40). Norwood, NJ: Ablex Publishing.

Chafe, W. (1994). Discourse, consciousness, and time. Discourse, 2(1).

Dahan, D., Tanenhaus, M. K., \& Chambers, C. G. (2002). Accent and reference resolution in spoken-language comprehension. Journal of Memory and Language, 47, 292-314.

Ferguson, C. A. (1971). Absence of copula and the notion of simplicity. Pidginization and creolization of languages, 141-150.

Forster, K.I., \& Forster, J.C. (2003). DMDX: A Windows display program with millisecond accuracy (2003). Behavior Research Methods Instruments and Computers, Vol. 35, No. 1. pp. 116-124.

Fowler, C., \& Housum, J. (1987). Talkers' signaling of 'new' and 'old' words in speech and listeners' perception and use of the distinction. Journal of Memory and Language, 26, 489-504.

Fraundorf, S.H., Watson, D.G., \& Benjamin, A.S. (2015). Reduction in prosodic prominence predicts speakers' recall: Implications for theories of prosody. Language, Cognition, and Neuroscience, 30, 606-619.

Galati, A., \& Brennan, S. E. (2010). Attenuating information in spoken communication: For the speaker, or for the addressee? Journal of Memory and Language, 62(1), 3551.

Gregory, M. L., Raymond, W. D., Bell, A., Fosler-Lussier, E., \& Jurafsky, D. (1999). The effects of collocational strength and contextual predictability in lexical production. In Chicago Linguistic Society (35), pp. 151-166.

Grosz, B. J., Joshi, A. K., \& Weinstein, S. (1995). Centering: A framework for modelling the local discourse. Computational Linguistics, 21, 203-225.
Gundel, J. K., Hedberg, N., \& Zacharski, R. (1993). Cognitive status and the form of referring expressions. Language, 69(2), 274-307.

Henzl, V. (1979). 'Foreigner Talk in the Classroom', International Review of Applied Linguistics 17(2): 159-67.

Isaacs, A. M., \& Watson, D. G. (2010). Accent detection is a slippery slope: Direction and rate of F0 change drives listeners' comprehension. Language and cognitive processes, 25, 1178-1200.

James, C. (1986). Welsh foreigner talk: breaking new ground. Journal of Multilingual \& Multicultural Development, 7, 41-54.

Jurafsky, D., Bell, A., Gregory, M., \& Raymond, W. (2001). Evidence from reduction in lexical production. Frequency and the emergence of linguistic structure, 45, 229.

Lam, T. Q., \& Watson, D. G. (2010). Repetition is easy: Why repeated referents have reduced prominence. Memory \& cognition, 38, 1137-1146.

Lattey, E. (1981). Foreigner Talk in the US and Germany: Contrast and Comparison. Paper presented at the meeting of the Linguistic Society of America, New York. (ERIC Document Reproduction Service No. ED 221 064).

Lieberman, P. (1963). Some effects of context on the intelligibility of hearing and deaf children's speech. Language and Speech, 24, 255-264.

Mayo, L. H., Florentine, M., \& Buus, S. (1997). Age of second-language acquisition and perception of speech in noise. Journal of Speech and Hearing Research, 40, 686-693.

Meador, D., Flege, J. E., \& MacKay, I. R. (2000). Factors affecting the recognition of words in a second language. Bilingualism: Language and Cognition, 3, 55-67.

Nábělek, A. K., \& Donohue, A. M. (1984). Perception of consonants in reverberation by native and non-native listeners. Journal of the Acoustic Society of America, 75, 632-634.

Nelson, D.K. (1992) 'The Foreigner Talk of a Family Physician: An Observational Study', ERIC Documents ED 3553826.

Ramamurti, R. (1980). Strategies involved in talking to a foreigner. PENN Review of Linguistics, 4, 84-93.

Rogers, C. L., Lister, J. J., Febo, D. M., Besing, J. M., \& Abrams, H. B. (2006). Effects of bilingualism, noise, and reverberation on speech perception by listeners with normal hearing. Applied Psycholinguistics, 27, 465-485.

Samuel, S. G., \& Troicki, M. (1998). Articulation quality is inversely related to redundancy when children or adults have verbal control. Journal of Memory and Language, 39, 175-194.

Scarborough, R., Dmitrieva, O., Hall-Lew, L., Zhao, Y., \& Brenier, J. (2007). An acoustic study of real and imagined foreigner-directed speech. Journal of the Acoustical Society of America, 121, 3044.

Snodgrass, J. G., \& Vanderwart, M. (1980). A standardized set of 260 pictures: norms for name agreement, image agreement, familiarity, and visual complexity. Journal of experimental psychology: Human learning and memory, 6, 174.

Szekely, A., Jacobsen, T., D’Amico, S., Devescovi, A., Andonova, E., Herron, D., Lu, C. C., Pechmann, T., Pleh, C., Wicha, N., Federmeier, K., Gerdjikova, I., Gutierrez, G., Hung, D., Hsu, J., Iyer, G., Kohnert, K., Mehotcheva, 
T., Orozco-Figueroa, A., Tzeng, A., Tzeng, O., Arevalo, A., Vargha, A., Butler, A. C., Buffington, R., \& Bates, E. (2004). A new on-line resource for psycholinguistic studies. Journal of Memory and Language, 51, 247-250.

Takata, Y., \& Nábělek, A. K. (1990). English consonant recognition in noise and in reverberation by Japanese and American listeners. Journal of the Acoustic Society of America, 88, 663-666.

Tarone, E. (1980). Communication strategies, foreigner talk and repair in interlanguage. Language Learning, 30, 417-431.
Terken, J., \& Nooteboom, S. G. (1987). Opposite effects of accentuation and deaccentuation on verification latencies for given and new information. Language and Cognitive Processes, 2, 145-163.

Watson, D. G., Arnold, J. E., \& Tanenhaus, M. K. (2008). Tic Tac TOE: Effects of predictability and importance on acoustic prominence in language production.Cognition, 106, 1548-1557.

Wooldridge, B. (2001). Foreigner Talk: An important element in cross-cultural management education and training. International Review of Administrative Sciences, 67, 621-634. 